\title{
Set Up and Practice of a Model of "Integrated-Into-Clinic" in the Teaching of Dental Materials
}

\author{
Zhao Xinyi, Tang Lihui, Li Shibao, Gong Xu \\ State Key Laboratory of Military Stomatology \& National Clinical Research Center for Oral Diseases \& \\ Shaanxi Key Laboratory of Stomatology, Department of Dental Materials, School of Stomatology, the Fourth \\ Military Medical University, Xi'an 710032, China
}

*Corresponding Author: Zhao Xinyi, State Key Laboratory of Military Stomatology \& National Clinical Research Center for Oral Diseases \& Shaanxi Key Laboratory of Stomatology, Department of Dental Materials, School of Stomatology, the Fourth Military Medical University, Xi'an 710032, China

\begin{abstract}
Science of Dental Materials, an important foundation course for dentistry, is related to dental clinical professional courses closely. Traditional teaching of Science of Dental Materials is separated from dental clinical professional courses, resulting in separating of the knowledge of dentistry. In this article, to strength the combination of Science of Dental Materials and clinical professional courses, a teaching model of "integrated-into-clinic" was introduced to the teaching of Science of Dental Materials, in which the teaching was separated into four parts and integrated into related clinical teaching blocks. After application of the model, the time teacher spend in explaining related clinical concept and principle in classroom decreased $69 \% \sim 70 \%$ and student's interest in Science of Dental Materials increased significantly, resulting in an average $8.1 \%$ increase of test scores.
\end{abstract}

Keywords: Dentistry, The Science of Dental Materials, Education, Teaching Model, Integrated-Into-Clinic

The science of dental materials is a course that provides an introduction of the composition, physical and mechanical properties, biocompatibility, application in dentistry and manipulative variables, aiming to develop the students' ability to select a appropriate restorative materials for a given case and apply the materials correctly. It is a basic course of dentistry and provides a lot of fundamental concepts and knowledge for dental clinical courses, thus it is closely related to dental clinical practice. On the other hand, many concepts, principles and terminology of clinical dentistry will be encountered during the teaching and learning of science of dental materials. However, under the traditional subject-centered curriculum, the teaching of dental basic courses like Science of Dental Materials were scheduled in the first semester after students' going into dental specialty studying ${ }^{[1]}$, along with Dental Anatomy Physiology and Dental Histopathology, being separated from the following teaching of dental clinical courses. Due to just beginning to learn dentistry, the students generally lack of dental background and elementary knowledge and especially lack of dental clinical related basic concepts, principles and knowledge and lack of ideal about clinical restoration processes ${ }^{[2]}$. This leads to the following problems: (1) A low efficiency in both teaching and learning. Due to the lack of relevant background and perceptual knowledge of dentistry, it is difficult for students to understand and imagine the clinical characteristics and clinical use of dental materials ${ }^{[3]}$. To solve this problem, teachers have to spend a lot of time to introduce relevant clinical background and concepts, which decrease the time for more important know edge points and thus affects the teaching efficiency of dental materials. But students still can not fully understand and grasp the relevant knowledge and the phenomenon of learning by rote exist commonly among students, which decreases their learning efficiency. (2) Students' showing low interest in learning dental materials. Under traditional teaching organization mode, the teaching of dental materials is arranged in before and separated from dental clinical courses, students are inactive and depressed and often feel the content is boring because they almost have no any ideals about the materials' application in dental clinic and aroused no echo ${ }^{[4]}$.

In addition, in the traditional subject-centered curriculum, students are discouraged from entertaining a different point of view than what textbook or teacher presents. The subject matter has already been chosen by teachers and deemed of value for students to learn. Thus it fosters not excitement about learning and knowledge, but passivity. 
In response to the above, a substantial reform has been carried out on the dental curricula of undergraduate programe in our university in the past eight years, which focus on how to pass on dental professional knowledge to students integrally and compositively. To achieve the aim, the teaching of all dental courses are divided into seven blocks based on dental disease and restoration, four blocks among which are closely related to dental materials: dental basic block which involves mainly independent dental basic knowledge, single tooth disease block which involves mainly restoration of tooth defect, dentition defect and abnormal block which involves the restoration of multi tooth defects or missing, maxillofacial disease block which involve the restoration of soft and hard tissue defects in maxillofacial region ${ }^{[5] .}$ This systematic teaching reform provides a good opportunity for the set up and practice of the " integration-into-clinic " teaching model of dental materials.

\section{The Set Up of the "Integration-Into-Clinic" Teaching Model of Dental Materials}

The keynotes of the teaching mode of " integration-into-clinic " in dental material is to integrate the teaching of dental materials into the related teaching blocks, aiming to integrate the knowledge of dental materials into the knowledge system of restoration of teeth defects and missing, so as to improve the teaching outcome and strengthen the guiding role of dental material knowledge in clinical practice.

The deliver of dental materials' teaching were separated and assigned to four closely related teaching blocks respectively according to clinical application of a material: oral basic medicine, single tooth disease, dentition defect and abnormal and maxillofacial diseases. The specific allotment and integration of dental materials's teaching of are as follows.

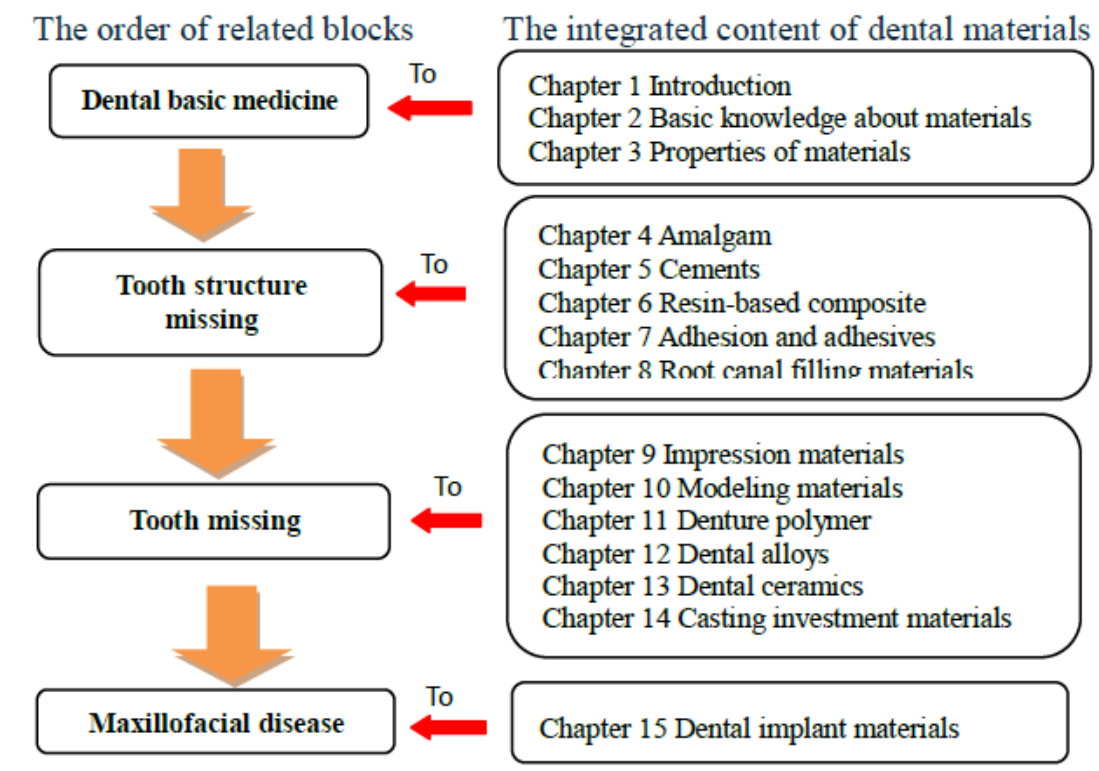

The teaching of chapter1 chapter 3 of Science of Dental Materials were integrated into the block of dental basic medicine because they are about elementary knowledge of materials and not closely relate to dentistry. The chapter2 chapter 7 were integrated into the block of tooth structure missing and their deliver are arranged prior to the session dental cavity restoration because they are about tooth filling materials and closely relate to dental cavity restoration.

The teaching of chapter 8 is integrated into the restoration of a tooth after treatment of endodontcs and periapical disease. The teaching of chapter 9 chapter 14 are integrated into the block of tooth missing because this chapters are about materials for prosthodontics. Specifically, chapter $9 \sim 11$ were integrated into the session of full denture restoration of this block and chapter 12 14 were integrated into the session of fix denture restoration. Through the above integration, most of the content of dental materials is integrated into the blocks closely related to their application and is closely combined with clinical practice.

This integration is not only an integration in form of, but also an integration in the link of lecture content, teaching design and methods, so as to provide students with clinical practice based dental material knowledge and consequently reflect the advantages of blocks teaching. In order to improve 
the quality of dental materials teaching and the depth of integration into dental clinical bolcks, we have taken following effective methods and measures and have achieved satisfactory results.

\section{MEANS TO IMPROVE THE "INTEGRATION-INTO-CLINIC"}

To improve the integration of dental materials teaching into dental clinical curriculum in promblebase teaching, following means have been carried out.

\subsection{Teacher Should Integrate into the Block Teaching First}

Traditionally the teaching of dental materials is scheduled in the elementary courses. during which only oral histopathology and oral anatomy and physiology are offered. Thus it is hard for teachers to quite the relevant knowledge and concept of dental clinical courses during teaching. Also teacher no need to consider how to bridge his/her lectures with clinical courses. But in the block teaching, lession of dental materials has become a part of this block completely, thus the teaching content and design of a single lession of dental materials must maintain a good connection and the logical relation with the previous and subsequent lessions. Furthermore, the terms, concepts and principles of some knowedge should be consistent within the block, avoiding contradictions and confusion. To this end, the teachers for dental materials are required to visit other classes within the block to know their teaching content, especially the classes before and after his/her own lession. In this way, teachers can better integrate his/her own lectures into the block in the content and teaching design and can readly establish a good link of knowledge between classes, and then can increase the systematicness and consistency of teaching knowledge and improve the clinical guiding role of dental material knowledge.

\subsection{The Multi-Subjects involved Collective Lessons Preparation}

In order to better integrate the knowledge points and avoid repeating teaching on one knowledge point within a block, it is important to list all knowledge points firstly and assign them reasonably to different subjects. For this purpose, a multi-subjects involved collective lesson preparation plan was created, which contains three regular preparations, one before, one in the initial stage and one the middle of the block teaching. Let's take the block of tooth structure missing for instance, a lesson preparation meeting was held one month before the block, teachers responsible for dental materials, cariology, operative dentistry and endodontics, prodthodontics and pediadontology attended the meeting. At the meeting, teachers from different subjects introduced respectively the content they tented to present, exchange teaching plans, discuss possible inconsistent terms, mechanism explanations, aiming to make sure on the accuracy and consistency of the teaching knowledge. In addition, the assignment of teaching contents within the block, teaching designing intended to use and fixation of key knowledge points were disscused and determined in reference to curriculum standards and syllabus. The years of experiences and skills in teaching of each teacher was also shared in the meeting. Through collective preparation and discussion, teachers of different subjects have a good understanding on other teachers' teaching contents and focuses, which can be reviewed and fully cited in his/her own lectures, presenting knowedges comprehensively and interconnectivity.

\section{Developing A Dental Materials Textbook Applies To "Integration-Into-Clinic" TEACHING}

In order to carry out "integration-into-clinic" teaching of dental materials successfully, in 2012 we organized to write and publish the fifth edition of "Science of Dental Materials", a textbook for national programming undergraduate teaching in medical colleges and universities, supported by the fourth national evaluation committee of textbooks in dentistry for medical colleges and universities and People's Health Publishing House ${ }^{[6]}$. Chapter structure in the textbook were divided according to materials' primary application rather than the nature of materials as in the former editions, with the aim of developing a knowledge structure of dental materials in close connection with dental clinic and facilitating the integration of dental materials teaching into the block teaching. The textbook also lay a foundation for practicing " integration-into-clinic " in the teaching of dental materials. The new textbook won the second prize of outstanding textbooks in Shaanxi Province in 2015.

To help students to better learn about dental materials, we organized experts from national major dental shools to write and publish a book of "Dental materials learning guidance and problem sets" (People's Health Press, 2012) ${ }^{[7]}$. The book is of great help to students to fully understand and grasp the difficult points of the textbook and to improve students' ability to analyze and solve problems. Many 
actual problems encountered in clinical practice were put into the problem sets, which is benefit for students to solve clinical practical problems in the future.

\section{OUTCOMES AFTER "INTEGRATION-INTO-CLINIC" TEACHING IN DENTAL MATERIALS}

\subsection{Remarkable Improvement in both Teaching and Learning Efficiency}

After application of "integration-into-clinic" in dental materials' teaching, both teaching and learning efficiency increased significantly. It is no longer necessary for teachers to spend a lot of time to introduce the material's clinical application process and related clinical knowledge and concepts because students have learned these knowledge in previous classes within the block, which enable teachers having more time to focus on teaching more important knowledges points and difficult points. The students are also readly to understand what teacher has presented in lession and to get hold of they have learned. Furthermore, students's self-directed learning ability has also increased. It is calculated that the time teacher spended on the introduction of related background know taken at lecture has reduce by $60 \% \sim 70 \%$.

\subsection{Enhancement of Student's Interest in Learning Dental Materials}

As a result of the integration of dental materials into dental clinical knowledge system, the role of dental material expertise in guiding clinical practice has been highlighted, which increased students' interest in learning dental materials, and thus the learning efficiency. It is calculated that students' exams scores increased by $8.1 \%$ on average after implementing the new teaching mode.

\subsection{The "Integration-Into-Clinic" Teaching Mode is Beneficial to PBL Teaching}

Problem-based learning (PBL) is a widely used teaching methods in medical education, which require students having related clinical knowledge. In the blocks teaching, students are readily to accept PBL in dental materials because they have learned relevant clinical concepts and knowledge, which enable them to solve clinic related problems on the basis of logical reasoning and thinking. For this reason, we schedule a PBL teaching about "How to select and apply restorative materials in tooth defect repair?" in the block of tooth structure missing, which was welcomed by the students and improves students' retention of knowledge.

\section{REFERENCE}

[1] $\mathrm{D} \mathrm{Li}, \mathrm{JJ} \mathrm{He}, \mathrm{R}$ Kuang. Some experiences on teaching reform of five years undergratuate programe in dentistry[J]. Northwest Medical Education 2003,11(4):286-288. DOI: 10.13555/ j.cnki.c.m.e.2003.04.009

[2] $\mathrm{D} \mathrm{Li}, \mathrm{JJ} \mathrm{He}$, R Kuang. A few experiences of reform in undergraduate teaching for 5-year stomatological program[J].Northwest Medical Education 2003,11(4):286-288. DOI: 10.13555/ j.cnki.c.m.e.2003.04.009

[3] JW Zheng, X Cao, XP Feng, ZY Zhang, JZ Zhang. Considerations and ideas on teaching reform of stomatology for cultivating innovative talents of high quality [J]. Shanghai Journal of Stomatology 2009,18(5): 536-539

[4] Y Yan, JQ Ling. Reform of curriculum and practical training in stomatology[J]. China Higher Medical Education 2013,(10): 71-72, DOI:10.3969/j.issn.1002-1701.2013.10.036

[5] $\mathrm{H} \mathrm{Lu}$, J Sun. Investigation on teaching mode in science of dental materials[J].Chinese Journal of Dental Materials and Devices 2012, 21(1):51-52

[6] L Kong, B Bo, XH Feng, et al. Stomatology education reform in the new situation of modern medicine development[J].Northwest Medical Education 2008,16(5):1014-1016, DOI: 10.13555/ j.cnki.c.m.e. 2008. 05.052

[7] XY Zhao. Science of dental materials, $5^{\text {th }}$ ed [M], Beijing: People's Medical Publishing House, 2012: 9-22

[8] XY Zhao. Learning guide and problem set for Science of Dental Materials[M], Beijing: People's Medical Publishing House, 2012:3-6

Citation: Zhao Xinyi et.al. "Set Up and Practice of a Model of "Integrated-Into-Clinic" in the Teaching of Dental Materials". International Journal of Humanities Social Sciences and Education (IJHSSE), vol 5, no. 6, 2018, pp. 103-106. doi: http://dx.doi.org/10.20431/2349-0381.0506013.

Copyright: () 2018 Authors. This is an open-access article distributed under the terms of the Creative Commons Attribution License, which permits unrestricted use, distribution, and reproduction in any medium, provided the original author and source are credited. 